\title{
A New Prediction System of Sepsis: A Retrospective, Clinical Study
}

\author{
Enhe Liu', Zhinan Zheng², Qiuye Kou1* \\ ${ }^{1}$ Department of Intensive care Unit, The Sixth Affiliated Hospital, Sun Yat-sen University, Guangzhou, China \\ ${ }^{2}$ Department of Anesthesia, The Sixth Affiliated Hospital, Sun Yat-sen University, Guangzhou, China \\ Email: *kouqiuye@126.com
}

How to cite this paper: Liu, E.H., Zheng, Z.N. and Kou, Q.Y. (2016) A New Prediction System of Sepsis: A Retrospective, Clinical Study. Modern Research in Inflammation, 5, 63-76.

http://dx.doi.org/10.4236/mri.2016.54007

Received: October 9, 2016

Accepted: November 1, 2016

Published: November 4, 2016

Copyright $\odot 2016$ by authors and Scientific Research Publishing Inc. This work is licensed under the Creative Commons Attribution International License (CC BY 4.0).

http://creativecommons.org/licenses/by/4.0/ (c) (i) Open Access

\begin{abstract}
Objective: Analyzing 6 biomarkers, such as procalcitonin (PCT), C-reactive protein (CRP), fibrinogen (Fib), lactate concentration (Lac), D-dimer (D-d), neutrophil ratio (NEUT\%) to figure out several sensitive indicators and establish a new prediction system of sepsis, which could achieve a higher sensitivity and specificity to predict sepsis. Methods: We collected 113 SIRS patients in ICU. According to their prognosis, all the patients were divided into two groups named sepsis and non-sepsis group according to the diagnostic criteria of sepsis. We recorded the general information and detected the plasma levels of the 6 biomarkers. Results: The plasma levels of NEUT\% and Fib between the two groups had no significant difference. PCT had the highest prediction accuracy of sepsis compared with other biomarkers. A predictive model was established, in which Lac, PCT, CRP were enrolled. The final prediction model was: $\operatorname{logit}(\mathrm{P})=0.314+0.105 \times \mathrm{Lac}(\mathrm{mmol} / \mathrm{l})+0.099 \times \mathrm{PCT}(\mathrm{ng} / \mathrm{mL})+0.012 \times$ $\mathrm{CRP}(\mathrm{mg} / \mathrm{L})$. The area under the curve of the prediction model was 0.893 , which was higher than every single biomarker involved in this study. Conclusion: The three serum biomarkers of Lac, PCT, CRP are used to establish a prediction model of sepsis: $\operatorname{logit}(\mathrm{P})=0.314+0.105 \times \mathrm{Lac}(\mathrm{mmol} / \mathrm{l})+0.099 \times \mathrm{PCT}(\mathrm{ng} / \mathrm{mL})+0.012 \times \mathrm{CRP}(\mathrm{mg} / \mathrm{L})$, which can better predict the occurrence of sepsis compared with other biomarkers.
\end{abstract}

\section{Keywords}

Sepsis, Biomarkers, Prediction System

\section{Introduction}

There are more than 750,000 with sepsis each year in United States, and 28\% of these patients (about 21 million) died. Although early aggressively anti-infection, fluid resuscitation and organ function support were given, about $9 \%$ of sepsis patients had 
developed into severe sepsis, and approximately 3\% of that had developed into sepsis shock [1]. There are more than 18 million cases with severe sepsis each year all over the world, and this number is rising with a speed of 1.5 percent to 8.0 percent per year [2]. Furthermore, treating sepsis would cost a lot of money and medical resource and bring tremendous burden to the individuals, families and society, so it is important to predict sepsis at early stage.

Over 100 kinds of biomarkers related to sepsis have been reported in literatures, which may have some predictive value to sepsis [3]. However, these biomarkers still have many deficiencies. For example, some studies reported C-reactive protein (CRP) had the lowest sensitivity value of $30 \%$, specificity value of $75 \%$, positive predictive value (PPV) of $31 \%$ and negative predictive value (NPV) of $81 \%$ [4] [5] [6]. Some studies questioned the ability of procalcitonin (PCT) to predict or diagnose sepsis, and they found that the current studies had some shortcomings. Most of the studies about PCT had a small sample capacity(less than 100 cases), the cases of these study were lack of universality, and most of the studies focused on specific subsets (ICU, trauma, burns, pediatrics, elderly patients) [7] [8]. Santana Reyes found that, interlukin-6 (IL-6) level had little difference between patients with systemic inflammatory response syndrome (SIRS) and sepsis, and the sensitivity (67\%) and specificity (65\%) of IL-6 was low, which suggested that IL-6 was not a good indicator to sepsis [9]. Therefore, some researches showed that there was no perfect single indicator which could be used to predict the occurrence of sepsis, and using multiple markers to predict the occurrence of sepsis would be a hot point [3]. This study was designed to analyze 6 commonly used biomarkers in clinic, such as PCT, CRP, fibrinogen (Fib), lactate concentration (Lac), D-dimer (D-d), neutrophil ratio (NEUT\%) in order to figure out several sensitive indicators and establish a new prediction system of sepsis, which could achieve a higher sensitivity and specificity to predict sepsis at early stage.

\section{Materials and Methods}

\subsection{Study Subjects}

This was a retrospective study of clinical cases and all the medical records were collected from intensive care unit of the Sixth Affiliated Hospital of Sun Yat-sen University from January 2015 to January 2016. The enrolled cases should meet the following requirements: First, all the patients were more than 18 years old and less than 70 years old; second, The length of ICU stay of all cases were more than 3 days (including 3 days); third, the patients should perform two or more SIRS symptoms when transferred to ICU. SIRS symptoms included the temperature was more than $38^{\circ} \mathrm{C}$ or less than $36^{\circ} \mathrm{C}$, heart rate was more than 90 beats per minute, respiratory rate was more than 20 times per minute or $\mathrm{PaCO}_{2}$ was less than $32 \mathrm{mmHg}$ and the white blood cell (WBC) count was more than $12 \times 10^{9} / \mathrm{L}$ or less than $4 \times 10^{9} / \mathrm{L}$.

Cases were excluded if the patients were in the state of immune suppression (such as patients of immune system disease, bone marrow transplant or solid organ transplantation, or long-term use of steroids), with leukopenia (WBC $<1.0 \times 10^{9} / \mathrm{L}$ ) or agranulo- 
cytosis (WBC $<0.5 \times 10^{9} / \mathrm{L}$ ) or hematologic malignancies, dead or discharged from ICU within 12 hours, with cachexia, or had been diagnosed with sepsis.

According to the definitions of 1991 ACCP/SCCM Sepsis Directory and 2001 SCCM/ESICM/ACCP/ATS/SIS International Sepsis Definition Conference [10] [11], which was shown in Table 1, the patients were divided into non-sepsis group and sepsis group according to their prognosis.

Table 1. Diagnostic criteria for sepsis.

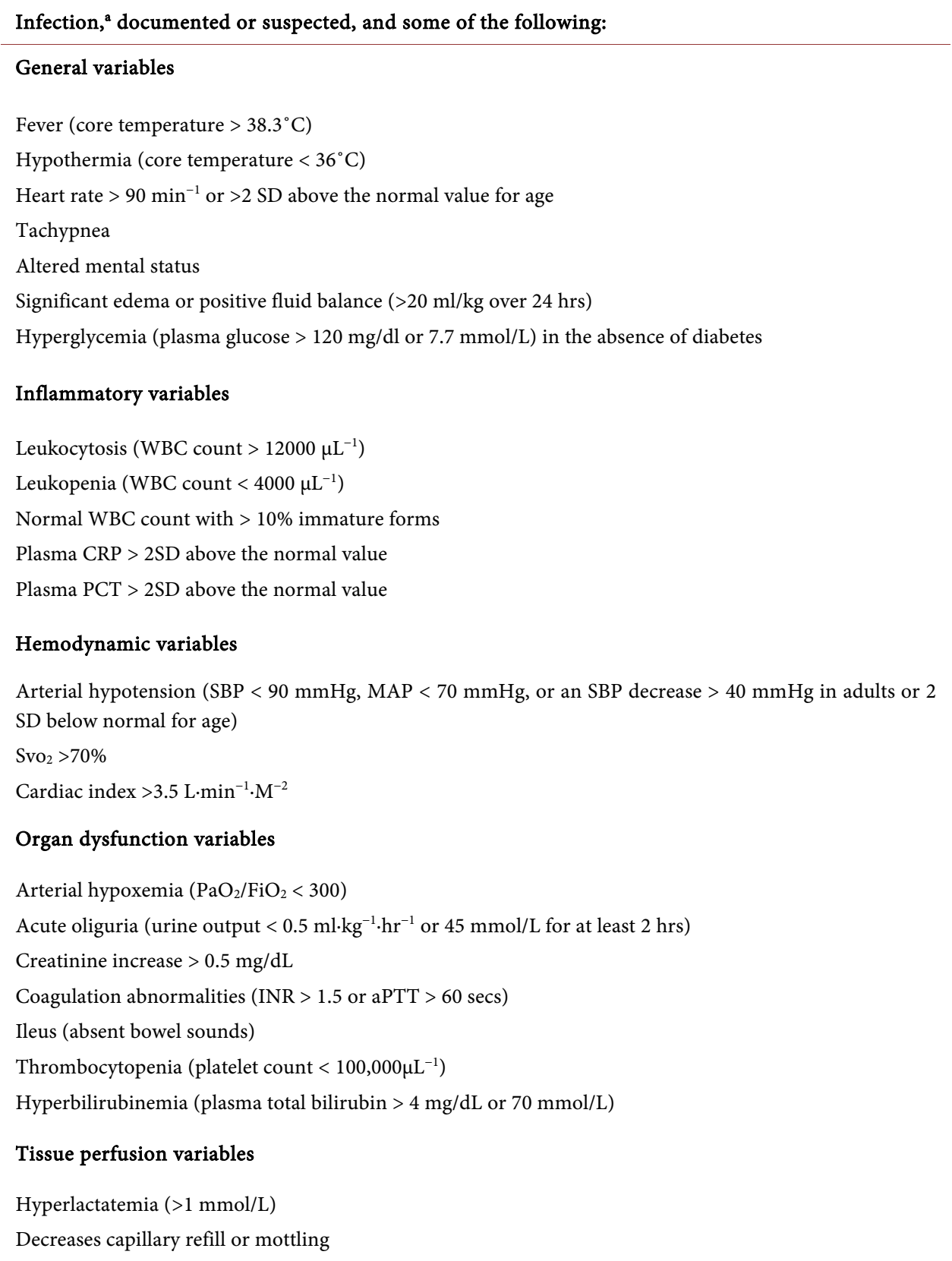

WBC, white blood cell; SBP, systolic blood pressure; MAP, mean arterial blood pressure; $\mathrm{Svo}_{2}$, mixed venous oxygen saturation; INR, international normalized ratio; aPTT, activated partial thromboplastin time. ${ }^{\text {anfection defined as a }}$ pathologic process induced by a microorganism. 


\subsection{Data Collection}

We collected the information including age, gender, underlying diseases, the surgical site, vital signs (temperature, respiration, heart rate, and blood pressure), microbial culture results, the site of infection. We collected plasma level of PCT, CRP, Fib, Lac, D-dimer and NEUT\% from the first day to the last day in ICU or the day that the patient was diagnosed as sepsis. The microbiological culture results of drainage fluid, sputum and blood were recorded, of which drainage fluid and sputum culture were kept every day in ICU and the blood culture was kept only when the patient's temperature was more than $38^{\circ} \mathrm{C}$. The plasma level of PCT, CRP, Fib, D-d and NEUT\% was measured by the medical laboratory department of the Sixth Affiliated Hospital of Sun Yat-sen University. The plasma level of PCT and CRP was measured by immunochromatography and performed by using Norman NRM411 automatic chemiluminiscence analyzer (Norman Inc., Nanjing, China). The plasma level of Fib and D-d was measured by using Precil C2000-A automatic blood coagulation instrument (Precil Inc., Beijing, China). The plasma level of NEUT\% was measured by using Sysmex XE-2100 hematology analyzer (Sysmex Inc., Cobe, Japan). Lac was measured by using the Nova stat profile critical care xpress (Nova Inc, USA,) of ICU. Microbiological culture was performed by using BacT/ALERT 3D60 automatic blood culture system (Biomérieux, France).

\subsection{Statistical Analysis}

The general information was descriptively analyzed. Continuous variables were presented as mean \pm standard deviation of the mean (SD). Differences of age, vital signs and biomarker levels between the two groups were determined using two-tailed Student's $t$ test. The performance of each biomarker and the prediction model as a sepsis prediction was demonstrated with receiver operating characteristic (ROC) analysis. The logistic regression was used to create the new prediction system. Statistical analysis was performed by using SPSS 16.0 statistical software package (SPSS Inc., Chicago, IL, USA). A value of $P<0.05$ was considered statistically significant.

\section{Results}

\subsection{The Characteristics of the Patients}

From January 2015 to January 2016, a total of 489 critically ill patients entered ICU, of which 225 patients was diagnosis as SIRS, but only 113 cases met the inclusion criteria and were enrolled in the study. Exclude cases include 2 children, 51 organ transplant patients, 2 autoimmune diseases patients, 1 hematologic malignancies patient, 4 cachexia patients, 3 patients who had used immunosuppressive drugs, 5 patients who died or discharged within 12 hours, and 44 patients without complete information.

In the 113 enrolled cases, 69 (61\%) patients had developed into sepsis, while the other $44(39 \%)$ were not. The difference of age composition was statistically significant between sepsis and non-sepsis groups. Non-sepsis patients were younger than sepsis patients ( $61 \pm 11$ vs. $52 \pm 8, P<0.001)$. Meanwhile, we found that body temperature 
and systolic blood pressure had no statistical difference. The difference was statistically significant on heart rate between the two groups ( $97 \pm 7$ vs. $85 \pm 4, P=0.033$ ). Because a large portion of the patients had no spontaneous breathing after surgeries when they entered ICU, the respiratory rate was not analyzed. The characteristics of the enrolled patients were shown in Table 2.

\subsection{Microorganism Characteristics}

Sixty-nine cases of 113 were diagnosed with sepsis, including 55 (79.7\%) with positive microbiological culture and $14(20.3 \%)$ with negative microbiological culture. There were 42 cases $(60.9 \%)$ with single bacterial infection, 3 cases $(4.3 \%)$ with single fungal infection, 10 cases (14.5\%) with mixed bacterial infection, and 14 cases (20.3\%) with

Table 2. The characteristics of the enrolled patients.

\begin{tabular}{|c|c|c|c|c|}
\hline Characteristics & All Patients & Sepsis Patients & Non-sepsis Patients & P Value \\
\hline Case number & 113 & 69 & 44 & \\
\hline Age (Year) & $58 \pm 12$ & $61 \pm 11$ & $52 \pm 8$ & $<0.001$ \\
\hline \multicolumn{5}{|l|}{ Gender } \\
\hline male & 72 & 46 & 26 & \\
\hline Female & 41 & 23 & 18 & \\
\hline \multicolumn{5}{|l|}{ Surgery sites } \\
\hline Gastroenteric Surgery & 32 & 22 & 10 & \\
\hline Hepatobiliary Surgery & 44 & 30 & 16 & \\
\hline Vascular Surgery & 14 & 9 & 5 & \\
\hline Urinary Surgery & 2 & 1 & 1 & \\
\hline Orthopedic Surgery & 2 & 1 & 1 & \\
\hline Thoracic Surgery & 14 & 7 & 7 & \\
\hline Internal Medicine & 3 & 2 & 1 & \\
\hline \multicolumn{5}{|l|}{ Underlying disease } \\
\hline Diabetes & 23 & 13 & 10 & \\
\hline Hypertension & 45 & 27 & 18 & \\
\hline Cardiovascular Disease & 19 & 10 & 9 & \\
\hline Renal Insufficiency & 8 & 5 & 3 & \\
\hline Cirrhosis & 10 & 5 & 5 & \\
\hline \multicolumn{5}{|l|}{ Vital signs } \\
\hline Temperature $\left({ }^{\circ} \mathrm{C}\right)$ & $36.6 \pm 0.7$ & $36.7 \pm 0.6$ & $36.4 \pm 0.7$ & 0.15 \\
\hline Heart rate (per minute) & $89 \pm 10$ & $97 \pm 7$ & $85 \pm 4$ & 0.033 \\
\hline Respiratory rate (per minute) & $17 \pm 7$ & $21 \pm 5$ & $18 \pm 8$ & - \\
\hline Systolic Pressure (mmHg) & $123 \pm 13$ & $121 \pm 10$ & $124 \pm 9$ & 0.17 \\
\hline
\end{tabular}

$\mathrm{P}<0.05$ means the difference was statistically significant between sepsis and non-sepsis groups. 
Table 3. Infection categorization, infection sites and etiologic agents of sepsis patients.

\begin{tabular}{|c|c|c|}
\hline Variable & Number of Cases (N) & Proportion (\%, N/69) \\
\hline \multicolumn{3}{|l|}{ Infection categorization } \\
\hline Identified Etiologic Agent & 55 & 79.7 \\
\hline No Identified Etiologic Agent & 14 & 20.3 \\
\hline \multicolumn{3}{|l|}{ Site of infection } \\
\hline Lung & 27 & 38.5 \\
\hline Intra-Abdominal & 17 & 25.2 \\
\hline Blood & 11 & 16.3 \\
\hline Biliary Tract & 2 & 2.90 \\
\hline Urinary Tract & 2 & 2.90 \\
\hline Operative Incision or Wounds & 4 & 6.10 \\
\hline \multicolumn{3}{|l|}{ Etiologic agent } \\
\hline Escherichia Coli & 16 & 23.2 \\
\hline Klebsiella Pneumoniae & 19 & 27.5 \\
\hline Pseudomonas Aeruginosa & 8 & 11.6 \\
\hline Acinetobacter Baumannii & 8 & 11.6 \\
\hline Stenotrophomonas Maltophilia & 3 & 4.35 \\
\hline Proteus Mirabilis & 3 & 4.35 \\
\hline Enterobacter Aerogenes & 2 & 2.90 \\
\hline Staphylococcus Epidermidis & 3 & 4.35 \\
\hline Staphylococcus Aureus (Including MRSA) & 2 & 2.90 \\
\hline Staphylococcus Haemolyticus & 2 & 2.90 \\
\hline Enterococcus Faecium & 8 & 11.6 \\
\hline Enterococcus Faecalis & 7 & 10.1 \\
\hline Gram-Positive Cocci & 22 & 31.9 \\
\hline Gram-Negative Bacillus & 59 & 85.5 \\
\hline Candida Albicans & 11 & 15.9 \\
\hline Candida Glabrata & 5 & 7.25 \\
\hline Candida Parapsilosis & 4 & 5.80 \\
\hline
\end{tabular}

mixed bacterial and fungal infections. Infection categorization, infection sites and etiologic agents are shown in Table 3.

Sixteen species of pathogenic microbial were cultured, of which 7 kinds of Gramnegative bacilli were cultured, and the infection rate in sepsis patients was $85.5 \%$. Five kinds of Gram-positive cocci were cultured, and the infection rate in sepsis patients was 31.9\%, which were mainly Enterococcus faecium and Enterococcus faecalis. Three species of Fungi were cultured, and the infection rate in sepsis patients was $29.0 \%$, which were mainly Candida albicans. 


\subsection{Levels of Plasma PCT, CRP, Fib, Lac, D-d, and NEUT\%}

The levels of plasma PCT, CRP, Fib, Lac, D-d, and NEUT\% of 113 patients were reviewed. We found that the levels of PCT, CRP, D-d, Lac of sepsis patients were higher than that of non-sepsis patients $(P<0.05)$, while the levels of NEUT\%, Fib were not statistically different between the two groups $(P>0.05)$. The comparison of the biomarkers between sepsis group and non-sepsis group are shown in Table 4.

\subsection{Prediction Value of PCT, CRP, NEUT\%, Fib, D-d and Lac to Sepsis}

The ROC curve to the prediction value of PCT, CRP, NEUT\%, Fib, Lac, D-d were shown in Figure 1. PCT could distinct non-sepsis patients and sepsis patients with high accuracy, and the AUC of PCT was 0.803 (95\% CI, $0.735-0.871, P=0.000$ ), higher than the other biomarkers. PCT, CRP, Lac, D- $d$ and NEUT\% were sensitive indicators to predict sepsis. Fib has the worst predictive capability.

\subsection{Construction of Prediction System for Sepsis}

In this study, we took all 6 biomarkers into logistic regression analysis (backward method) to build predictive models. Three biomarkers of Lac, PCT, and CRP eventually were picked out as Table 5 . The final prediction system was $\operatorname{Logit}(\mathrm{P})=0.314+0.105 \times$ $\mathrm{Lac}(\mathrm{mmol} / \mathrm{l})+0.099 \times \mathrm{PCT}(\mathrm{ng} / \mathrm{mL})+0.012 \times \mathrm{CRP}(\mathrm{mg} / \mathrm{L})$.

\subsection{Analysis of Prediction System for Sepsis}

The ROC curve to the prediction value of the new predictive system was shown in Figure 2. We found that the AUC of this system was 0.834 (95\% CI, $0.773-0.895, P=$ 0.000 ), higher than any of the above 6 indicators, indicating that the prediction accuracy for sepsis was higher than any individual indicators. The cutoff value of this system was 0.628 .

\section{Discussion}

PCT, CRP, Fib, Lac, D-d, and NEUT\% are used frequently in most hospitals. These biomarkers represent different parts of pathophysiologic change in sepsis, including the inflammatory response (PCT, CRP, NEUT\%), coagulation (D-d, Fib), and oxygen

Table 4. Comparison of the biomarkers between sepsis group and non-sepsis group.

\begin{tabular}{cccc}
\hline Variable & Non-sepsis group $(\mathrm{N}=52)$ & Sepsis Group $(\mathrm{N}=80)$ & $P$ value \\
\hline NEUT\% (\%) & $0.63 \pm 0.31$ & $0.72 \pm 0.25$ & 0.065 \\
FIB (g/L) & $3.35 \pm 1.43$ & $3.30 \pm 1.71$ & 0.826 \\
D-d (ug/L) & $860.85 \pm 620.15$ & $1326.29 \pm 1870.94$ & 0.021 \\
PCT (ng/mL) & $3.45 \pm 4.83$ & $36.02 \pm 101.29$ & 0.001 \\
CRP (mg/L) & $92.35 \pm 69.06$ & $139.96 \pm 93.66$ & $<0.001$ \\
LAC (mmol/L) & $1.32 \pm 1.38$ & $2.43 \pm 2.88$ & 0.001 \\
\hline
\end{tabular}

$\mathrm{P}<0.05$ means the difference was statistically significant between sepsis and non-sepsis groups. 


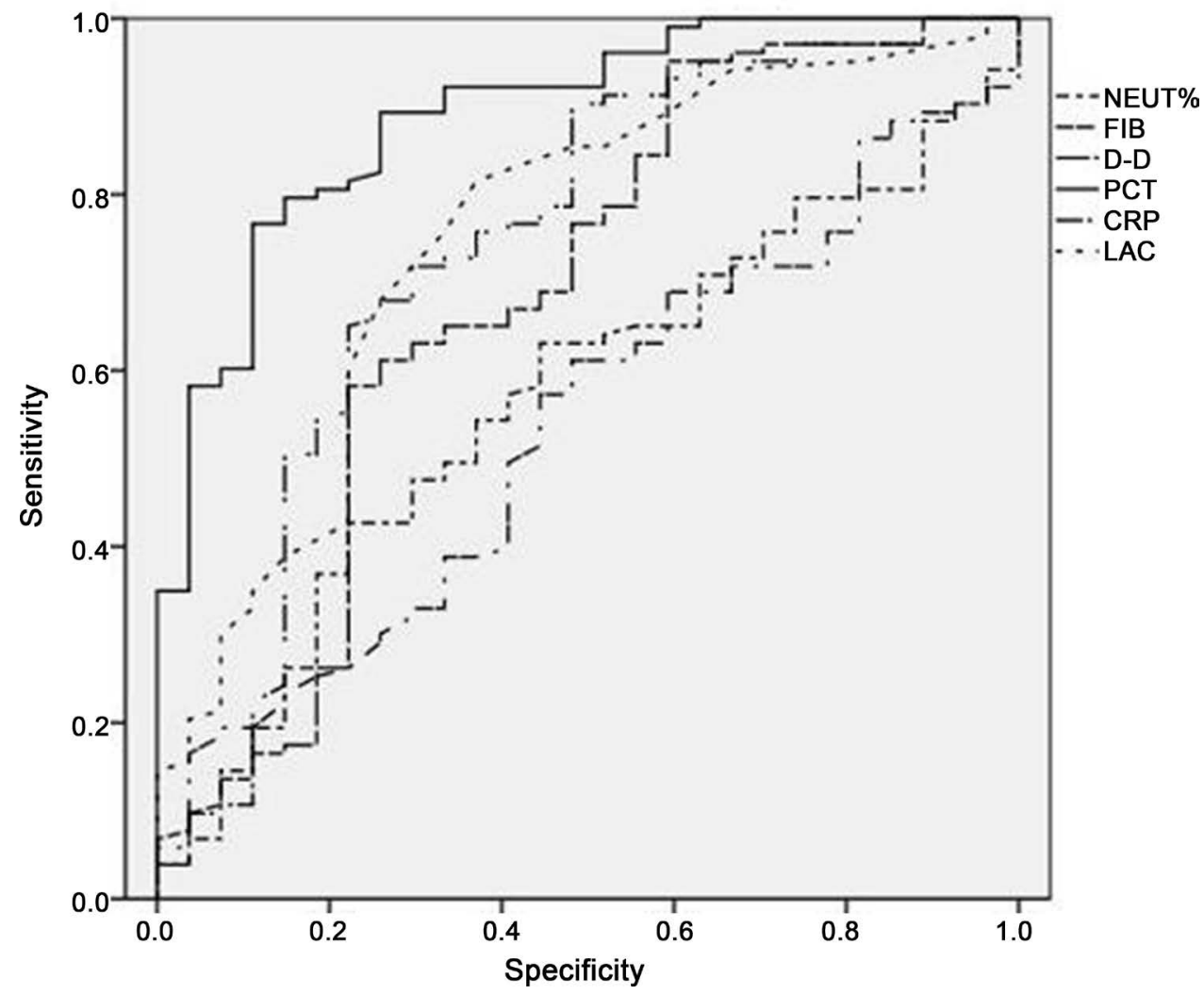

Figure 1. ROC Curve Analysis of PCT, CRP, NEUT\%, Fib, D-d and Lac to sepsis. The AUC of PCT was 0.803 (95\% CI, 0.735-0.871, $P=0.000$ ), higher than the other biomarkers. The AUC of Lac, CRP, NEUT\%, D-d, FIB was 0.725 (95\% CI, 0.645 - 0.804, $P=0.000), 0.682$ (95\% CI, 0.599 $0.765, P=0.000), 0.604(95 \% \mathrm{CI}, 0.518-0.691, P=0.022), 0.597(95 \% \mathrm{CI}, 0.510-0.685, P=$ $0.032), 0.471(95 \% \mathrm{CI}, 0.383-0.559, P=0.523)$, respectively.

Table 5. Building predictive system by logistic regression analysis.

\begin{tabular}{ccccccccc}
\hline & B & S.E. & Wald & df & Sig. & $\operatorname{Exp}(\mathrm{B})$ & \multicolumn{2}{c}{$95.0 \%$ C.I. for EXP(B) } \\
\hline Lac & 0.105 & 0.003 & 17.279 & 1 & 0.000 & 0.988 & 0.982 & 0.993 \\
PCT & 0.099 & 0.036 & 7.452 & 1 & 0.006 & 1.102 & 1.028 & 1.182 \\
CRP & 0.012 & 0.003 & 8.557 & 1 & 0.003 & 1.009 & 1.003 & 1.015 \\
Constant & 0.314 & 0.472 & 0.506 & 1 & 0.477 & 1.399 & & \\
\hline
\end{tabular}

metabolism (Lac). Each indicator can predict the occurrence of sepsis. However, when they are used singly, the accuracy of the prediction to sepsis is not ideal as mentioned before. PCT is a good predictive biomarkers for sepsis. In our study, PCT could distinguish non-sepsis and sepsis group well, and the difference between the two groups was statistically significant. Its diagnostic accuracy was the best of all biomarkers of this study. PCT has been considered as the most promising biomarkers for infection, which is produced and expressed after cytokines (IL-6, tumor necrosis factor, etc.) stimulates a variety of cells such as brain cells, or neutrophils. The levels of PCT can rapidly 


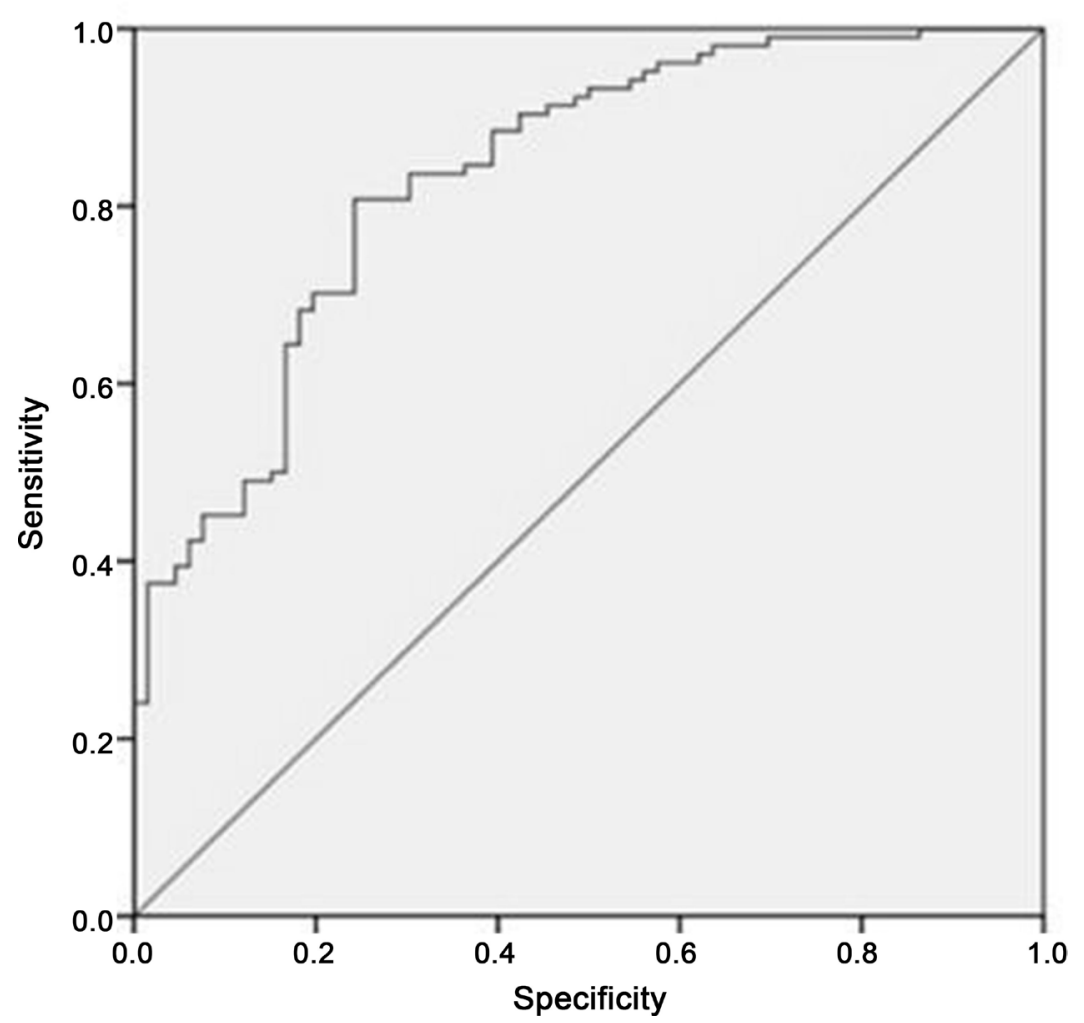

Figure 2. ROC Curve Analysis for the new prediction system. The AUC of the system was 0.834 (95\% CI, $0.773-0.895, P=0.000$ ), higher than PCT, CRP, NEUT\%, Fib, D-d or Lac.

increase after infection and there is a significant correlation between PCT level and the severity of infection [12]. Furthermore, its peak occurs at the time of $24 \mathrm{~h}$ after sepsis, earlier than CRP, IL-6. This feature can help clinicians to predict sepsis earlier. Most of the studies considered that the sensitivity and specificity of PCT for predicting or diagnosing sepsis were higher than other biomarkers. Although PCT has many advantages to predict sepsis, there are also more and more literatures beginning to question its accuracy. A meta-analysis study showed that diagnosis value of PCT to sepsis was not high enough, in which both the average sensitivity and specificity of PCT were only $71 \%$, and AUC was just 0.78 [13]. Our study also found that between sepsis and non-sepsis group, using PCT alone did not have the best predictive effect.

$\mathrm{CRP}$ is an acute phase proteins, which may be activated by infection. As described by literatures, the accuracy of predicting sepsis had a larger fluctuation. Some scholars believed that variation per day of CRP exceeding $41 \mathrm{mg} / \mathrm{L}$ was appropriate to predict the occurrence of sepsis with the sensitivity of $92.1 \%$ and the specificity of $72.4 \%$ [14]. But Luzzani found that the diagnosis sensitivity and specificity of CRP for sepsis was only $69 \%$ and $61 \%$, and they believed the prediction value of CRP to sepsis is not high [15]. Our study found that CRP could distinguish non-sepsis and sepsis well. However, the accuracy of CRP was not high, the AUC was 0.682 (95\% CI, $0.599-0.765, P=0.000$ ). To interpret this part of the results we can start from the CRP features. The level of $\mathrm{CRP}$ can rise quickly in 4 hours after infection. The highest concentration may reach 
2000 times than the normal value, while declines rapidly after eliminating the infection, so it can reflect the occurrence and development process of infection. But there are so many factors that can influence CRP, such as trauma, burns, major surgery, cancer. The majority of cases enrolled in this study were post-operative patients, which could affect the predictive ability of CRP. Therefore, all above demonstrated us again that using CRP alone as a predictor for sepsis was not enough.

A large number of inflammatory factors and cytokines release in SIRS patients, so abnormal coagulation and fibrinolysis often exist in these patients. Gando S showed that sepsis could lead to activation of the extrinsic coagulation pathway, resulted in the formation of thrombin and Fib, and then tumor necrosis factor-mediated plasminogen activator caused activation of kinase, which could significantly degrade Fib to D-d [16]. The study by Kollef found that plasma D-d levels exceeding $1000 \mathrm{ng} / \mathrm{mL}$ could predict the occurrence of sepsis [17]. Rodelo JR also found that the plasma D-d levels of sepsis patients were much higher than that of non-sepsis patients [18]. Although these literatures confirmed that the predictive value of D-d, a variety of factors can affect the concentration of D-d and Fib, including hematology, oncology and clinical transfusion. Our study found that $\mathrm{D}-\mathrm{d}$ can be used to distinguish non-sepsis and sepsis group. The difference between the two groups was statistically significant $(860.85 \pm 620.15$ vs. $1326.29 \pm 1870.94, P=0.021$ ), which showed that coagulation in sepsis patients had been affected. However, the difference of Fib between the two groups was not significant ( $3.35 \pm 1.43$ vs. $3.30 \pm 1.71, P=0.826)$. The results of this part demonstrated that using either Fib or D-d alone could not predict the occurrence of sepsis well.

In recent years, there are many biomarkers which could predict sepsis being found, including: lipopolysaccharide-binding protein, interleukin-8, interleukin-10, triggering receptor expressed on myeloid cell-1, endothelin-1, etc. [19] [20] [21] [22] [23]. But the perfect indicator which can well predict the occurrence of sepsis have not been found by now. Therefore, the latest point is using comprehensive detection of multiple biomarkers to improve diagnostic accuracy for sepsis [24] [25] [26].

There was little literature which used multiple biomarkers to predict sepsis [27]. Kofoed's study had compared four kinds of combinations, including one panel consisting of three predictive biomarker (soluble urokinase-type plasminogen activator receptor [V-SUPAR], soluble myeloid cells triggers receptor -1 [sTREM-1], macrophage inhibitory factor $[\mathrm{MIF}]), \mathrm{V}$-suPAR and age, sTREM and age, as well as the panel and age, to predict 30/180-day mortality in community-acquired infections patients [28]. Selberg and his colleagues created a scoring system consisting of PCT and activation of complement 3 (C3a), and compared the ability for distinguishing sepsis and non-sepsis patient with PCT, interleukin-6, C3a, elastase and CRP. Finally they found scoring system can better distinguish the two groups than other biomarkers [29]. Shapiro formed a sepsis scoring system by using the neutrophil gelatinase-associated lipocalin, protein C, and IL-1 receptor antagonist to predict 72 hours prognosis for severe sepsis and septic shock patients [30]. Punyadeera collected 118 serum markers of 16 patients, and found that combined detection of matrix metalloproteinase-3 (MMP-3), matrix metallopro- 
teinase-10 (MMP-10), interleukin-1 $\alpha$, interferon-inducible protein-10 (IP-10), soluble interleukin-2R (sIL-2R), soluble fatty acid synthase (sFas), soluble tumor necrosis factor type I receptor protein (sTNF-R1), soluble advanced glycation endproducts receptor (sRAGE), granulocyte macrophage colony-stimulating factor (GM-CSF), interleukin- $1 \beta$, and eosinophil activation chemokine (Eotaxin) could better distinguish the severity of sepsis, and predict the risk of death in sepsis patients [31].

Not the same as the literature above, our study aimed to establish an early prediction model to sepsis for clinicians to make effective treatment timely. The final model system was $\operatorname{logit}(\mathrm{P})=0.314+0.105 \times \mathrm{Lac}(\mathrm{mmol} / \mathrm{l})+0.099 \times \mathrm{PCT}(\mathrm{ng} / \mathrm{mL})+0.012 \times$ $\mathrm{CRP}(\mathrm{mg} / \mathrm{L})$. Prediction accuracy of this system was better than any single indicators above. The AUC was 0.834 (95\% CI, 0.773 - 0.895, $\mathrm{P}=0.000)$.

The system still had only a medium predictive ability due to the small number of samples. Because of limitation of experimental conditions, some "good" indicators were not included (such as tumor necrosis factor, etc.). This was the limitation of this study. Further studies are needed.

\section{Conclusion}

The three serum biomarkers of Lac, PCT, CRP can establish a prediction system of sepsis which is: $\operatorname{logit}(\mathrm{P})=0.314+0.105 \times \mathrm{Lac}(\mathrm{mmol} / \mathrm{l})+0.099 \times \mathrm{PCT}(\mathrm{ng} / \mathrm{mL})+0.012 \times$ $\mathrm{CRP}(\mathrm{mg} / \mathrm{L})$. And the prediction system can better predict the occurrence of sepsis compared with other biomarkers.

\section{Declaration of Interests}

All authors have no interests to be declared.

\section{References}

[1] Christ-Crain, M., Morgenthaler, N.G., Struck, J., Harbarth, S., Bergmann, A. and Muller, B. (2005) Mid-Regional Pro-Adrenomedullin as a Prognostic Marker in Sepsis: An Observational Study. Critical Care, 9, R816-R824.

[2] Martin, G.S., Mannino, D.M., Eaton, S. and Moss, M. (2003) The Epidemiology of Sepsis in the United States from 1979 through 2000. The New England Journal of Medicine, 348, 1546-1554. http://dx.doi.org/10.1056/NEJMoa022139

[3] Chan, T. and Gu, F. (2011) Early Diagnosis of Sepsis Using Serum Biomarkers. Expert Review of Molecular Diagnostics, 11, 487-496. http://dx.doi.org/10.1586/erm.11.26

[4] Zecca, E., Barone, G., Corsello, M., Romagnoli, C., Tiberi, E., Tirone, C. and Vento, G. (2009) Reliability of Two Different Bedside Assays for C-Reactive Protein in Newborn Infants. Clinical Chemistry and Laboratory Medicine, 47, 1081-1084. http://dx.doi.org/10.1515/CCLM.2009.246

[5] Lannergard, A., Larsson, A., Friman, G. and Ewald, U. (2008) Human Serum Amyloid A (SAA) and High Sensitive C-Reactive Protein (hsCRP) in Preterm Newborn Infants with Nosocomial Infections. Acta Paediatrica, 97, 1061-1065. http://dx.doi.org/10.1111/j.1651-2227.2008.00814.x

[6] Groselj-Grenc, M., Ihan, A., Pavcnik-Arnol, M., Kopitar, A.N., Gmeiner-Stopar, T. and Derganc, M. (2009) Neutrophil and Monocyte CD64 Indexes, Lipopolysaccharide-Binding 
Protein, Procalcitonin and C-Reactive Protein in Sepsis of Critically Ill Neonates and Children. Intensive Care Medicine, 35, 1950-1958.

http://dx.doi.org/10.1007/s00134-009-1637-7

[7] Uzzan, B., Cohen, R., Nicolas, P., Cucherat, M. and Perret, G.Y. (2006) Procalcitonin as a Diagnostic Test for Sepsis in Critically Ill Adults and after Surgery or Trauma: A Systematic Review and Meta-Analysis. Critical Care Medicine, 34, 1996-2003. http://dx.doi.org/10.1097/01.CCM.0000226413.54364.36

[8] Simon, L., Gauvin, F., Amre, D.K., Saint-Louis, P. and Lacroix, J. (2004) Serum Procalcitonin and C-Reactive Protein Levels as Markers of Bacterial Infection: A Systematic Review and Meta-Analysis. Clinical Infectious Diseases, 39, 206-217.

http://dx.doi.org/10.1086/421997

[9] Santana, R.C., Garcia-Munoz, F., Reyes, D., Gonzalez, G., Dominguez, C. and Domenech, E. (2003) Role of Cytokines (Interleukin-1beta, 6, 8, Tumour Necrosis Factor-Alpha, and Soluble Receptor of Interleukin-2) and C-Reactive Protein in the Diagnosis of Neonatal Sepsis. Acta Paediatrica, 92, 221-227.

[10] Bone, R.C., Balk, R.A., Cerra, F.B., Dellinger, R.P., Fein, A.M., Knaus, W.A., Schein, R.M. and Sibbald, W.J. (1992) Definitions for Sepsis and Organ Failure and Guidelines for the Use of Innovative Therapies in Sepsis. The ACCP/SCCM Consensus Conference Committee. American College of Chest Physicians/Society of Critical Care Medicine. Chest, 101, 1644-1655. http://dx.doi.org/10.1378/chest.101.6.1644

[11] Levy, M.M., Fink, M.P., Marshall, J.C., Abraham, E., Angus, D., Cook, D., Cohen, J., Opal, S.M., Vincent, J.L. and Ramsay, G. (2003) 2001 SCCM/ESICM/ACCP/ATS/SIS International Sepsis Definitions Conference. Critical Care Medicine, 31, 1250-1256. http://dx.doi.org/10.1097/01.CCM.0000050454.01978.3B

[12] Gattas, D.J. and Cook, D.J. (2003) Procalcitonin as a Diagnostic Test for Sepsis: Health Technology Assessment in the ICU. Journal of Critical Care, 18, 52-58. http://dx.doi.org/10.1053/jcrc.2003.YJCRC11

[13] Tang, B.M., Eslick, G.D., Craig, J.C. and McLean, A.S. (2007) Accuracy of Procalcitonin for Sepsis Diagnosis in Critically Ill Patients: Systematic Review and Meta-Analysis. The Lancet Infectious Diseases, 7, 210-217. http://dx.doi.org/10.1016/S1473-3099(07)70052-X

[14] Povoa, P., Coelho, L., Almeida, E., Fernandes, A., Mealha, R., Moreira, P. and Sabino, H. (2006) Early Identification of Intensive Care Unit-Acquired Infections with Daily Monitoring of C-Reactive Protein: A Prospective Observational Study. Critical Care, 10, R63. http://dx.doi.org/10.1186/cc4892

[15] Luzzani, A., Polati, E., Dorizzi, R., Rungatscher, A., Pavan, R. and Merlini, A. (2003) Comparison of Procalcitonin and C-Reactive Protein as Markers of Sepsis. Critical Care Medicine, 31, 1737-1741. http://dx.doi.org/10.1097/01.CCM.0000063440.19188.ED

[16] Gando, S., Nanzaki, S., Sasaki, S., Aoi, K. and Kemmotsu, O. (1998) Activation of the Extrinsic Coagulation Pathway in Patients with Severe Sepsis and Septic Shock. Critical Care Medicine, 26, 2005-2009. http://dx.doi.org/10.1097/00003246-199812000-00030

[17] Kollef, M.H., Eisenberg, P.R. and Shannon, W. (1998) A Rapid Assay for the Detection of Circulating D-Dimer Is Associated with Clinical Outcomes among Critically Ill Patients. Critical Care Medicine, 26, 1054-1060. http://dx.doi.org/10.1097/00003246-199806000-00027

[18] Rodelo, J.R., De la Rosa, G., Valencia, M.L., Ospina, S., Arango, C.M., Gomez, C.I., Garcia, A., Nunez, E. and Jaimes, F.A. (2012) D-Dimer Is a Significant Prognostic Factor in Patients with Suspected Infection and Sepsis. American Journal of Emergency Medicine, 30, 1991-1999. http://dx.doi.org/10.1016/j.ajem.2012.04.033 
[19] Sakr, Y., Burgett, U., Nacul, F.E., Reinhart, K. and Brunkhorst, F. (2008) Lipopolysaccharide Binding Protein in a Surgical Intensive Care Unit: A Marker of Sepsis? Critical Care Medicine, 36, 2014-2022. http://dx.doi.org/10.1097/CCM.0b013e31817b86e3

[20] Livaditi, O., Kotanidou, A., Psarra, A., Dimopoulou, I., Sotiropoulou, C., Augustatou, K., Papasteriades, C., Armaganidis, A., Roussos, C., Orfanos, S.E. and Douzinas, E.E. (2006) Neutrophil CD64 Expression and Serum IL-8: Sensitive Early Markers of Severity and Outcome in Sepsis. Cytokine, 36, 283-290. http://dx.doi.org/10.1016/j.cyto.2007.02.007

[21] Heper, Y., Akalin, E.H., Mistik, R., Akgoz, S., Tore, O., Goral, G., Oral, B., Budak, F. and Helvaci, S. (2006) Evaluation of Serum C-Reactive Protein, Procalcitonin, Tumor Necrosis Factor Alpha, and Interleukin-10 Levels as Diagnostic and Prognostic Parameters in Patients with Community-Acquired Sepsis, Severe Sepsis, and Septic Shock. European Journal of Clinical Microbiology \& Infectious Diseases, 25, 481-491.

http://dx.doi.org/10.1007/s10096-006-0168-1

[22] Gibot, S., Kolopp-Sarda, M.N., Bene, M.C., Cravoisy, A., Levy, B., Faure, G.C. and Bollaert, P.E. (2004) Plasma Level of a Triggering Receptor Expressed on Myeloid Cells-1: Its Diagnostic Accuracy in Patients with Suspected Sepsis. Annals of Internal Medicine, 141, 9-15. http://dx.doi.org/10.7326/0003-4819-141-1-200407060-00009

[23] Kuklin, V., Kirov, M., Sovershaev, M., Andreasen, T., Ingebretsen, O.C., Ytrehus, K. and Bjertnaes, L. (2005) Tezosentan-Induced Attenuation of Lung Injury in Endotoxemic Sheep Is Associated with Reduced Activation of Protein Kinase C. Critical Care, 9, R211-R217. http://dx.doi.org/10.1186/cc3497

[24] Chan, T. and Gu, F. (2011) Early Diagnosis of Sepsis Using Serum Biomarkers. Expert Review of Molecular Diagnostics, 11, 487-496. http://dx.doi.org/10.1586/erm.11.26

[25] Tsalik, E.L., Jaggers, L.B., Glickman, S.W., Langley, R.J., van Velkinburgh, J.C., Park, L.P., Fowler, V.G., Cairns, C.B., Kingsmore, S.F. and Woods, C.W. (2012) Discriminative Value of Inflammatory Biomarkers for Suspected Sepsis. Journal of Emergency Medicine, 43, 97-106. http://dx.doi.org/10.1016/j.jemermed.2011.05.072

[26] Marshall, J.C. and Reinhart, K. (2009) Biomarkers of Sepsis. Critical Care Medicine, 37, 2290-2298. http://dx.doi.org/10.1097/CCM.0b013e3181a02afc

[27] Casserly, B., Read, R. and Levy, M.M. (2011) Multimarker Panels in Sepsis. Critical Care Clinics, 27, 391-405. http://dx.doi.org/10.1016/j.ccc.2010.12.011

[28] Kofoed, K., Andersen, O., Kronborg, G., Tvede, M., Petersen, J., Eugen-Olsen, J. and Larsen, K. (2007) Use of Plasma C-Reactive Protein, Procalcitonin, Neutrophils, Macrophage Migration Inhibitory Factor, Soluble Urokinase-Type Plasminogen Activator Receptor, and Soluble Triggering Receptor Expressed on Myeloid Cells-1 in Combination to Diagnose Infections: A Prospective Study. Critical Care, 11, R38. http://dx.doi.org/10.1186/cc5723

[29] Selberg, O., Hecker, H., Martin, M., Klos, A., Bautsch, W. and Kohl, J. (2000) Discrimination of Sepsis and Systemic Inflammatory Response Syndrome by Determination of Circulating Plasma Concentrations of Procalcitonin, Protein Complement 3a, and Interleukin-6. Critical Care Medicine, 28, 2793-2798.

http://dx.doi.org/10.1097/00003246-200008000-00019

[30] Shapiro, N.I., Trzeciak, S., Hollander, J.E., Birkhahn, R., Otero, R., Osborn, T.M., Moretti, E., Nguyen, H.B., Gunnerson, K.J., Milzman, D., Gaieski, D.F., Goyal, M., Cairns, C.B., Ngo, L. and Rivers, E.P. (2009) A Prospective, Multicenter Derivation of a Biomarker Panel to Assess Risk of Organ Dysfunction, Shock, and Death in Emergency Department Patients with Suspected Sepsis. Critical Care Medicine, 37, 96-104.

http://dx.doi.org/10.1097/CCM.0b013e318192fd9d 
[31] Punyadeera, C., Schneider, E.M., Schaffer, D., Hsu, H.Y., Joos, T.O., Kriebel, F., Weiss, M. and Verhaegh, W.F. (2010) A Biomarker Panel to Discriminate between Systemic Inflammatory Response Syndrome and Sepsis and Sepsis Severity. Journal of Emergencies, Trauma and Shock, 3, 26-35. http://dx.doi.org/10.4103/0974-2700.58666

Submit or recommend next manuscript to SCIRP and we will provide best service for you:

Accepting pre-submission inquiries through Email, Facebook, LinkedIn, Twitter, etc. A wide selection of journals (inclusive of 9 subjects, more than 200 journals)

Providing 24-hour high-quality service

User-friendly online submission system

Fair and swift peer-review system

Efficient typesetting and proofreading procedure

Display of the result of downloads and visits, as well as the number of cited articles

Maximum dissemination of your research work

Submit your manuscript at: http://papersubmission.scirp.org/

Or contact mri@scirp.org 